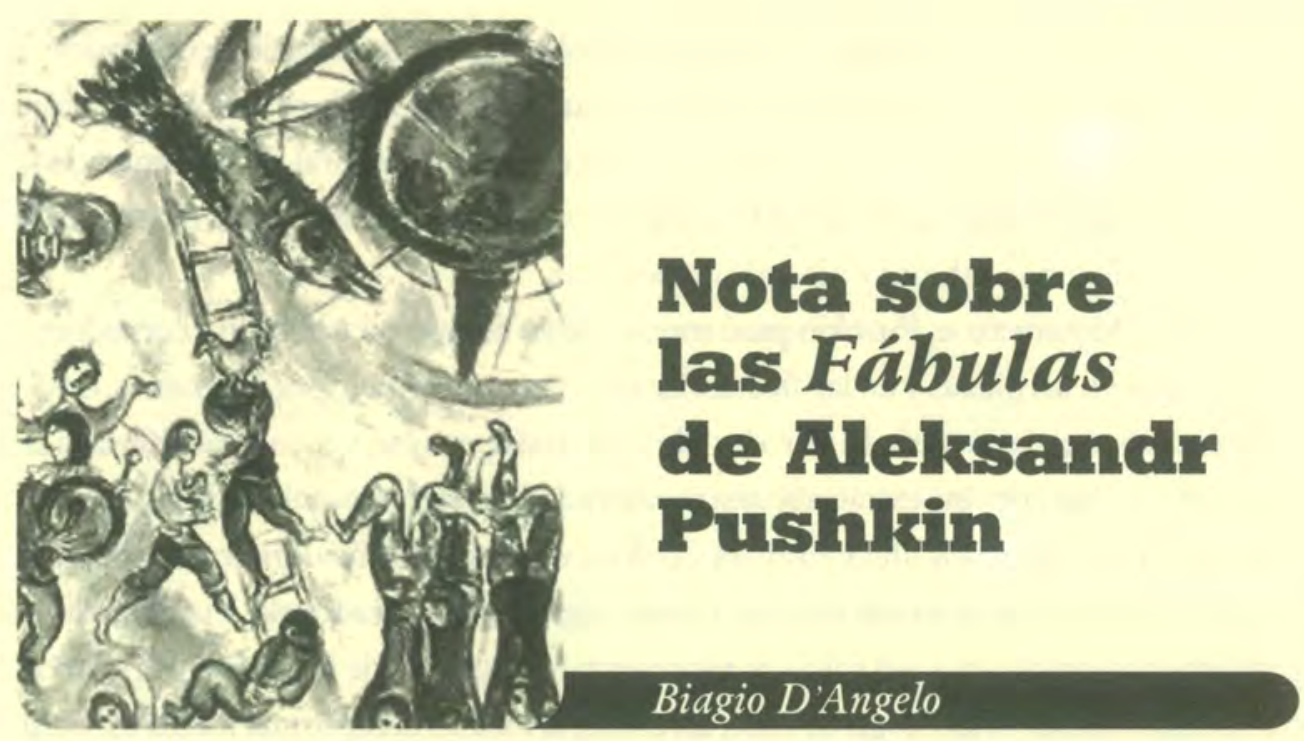

$\mathrm{E}$ n el momento triste y dramático del exilio en Mijáilovskoe, en el sur de Rusia, Aleksandr Pushkin dedica su tiempo a la elaboración de seis fábulas que representan uno de los puntos más altos de la lírica rusa del siglo XIX. Escritas entre 1830 y 1834, en un periodo en que el interés sobre la cultura popular había despertado las mentes y las plumas de escritores como Gogol, Dahl y Ershóv, las fábulas pushkinianas se configuran como un ciclo completo comprendido por «Fábula del Pope y de su obrero Baldá», «Fábula de la Osa», «Fábula del zar Saltán», «Fábula de la zarina muerta y sus siete héroes», «Fábula del Gallo de Oro» y, la que aquí presentamos en traducción, «Fábula del Pescador y del Pececito».

Por mucho tiempo, ciertas interpretaciones chauvinistas han indicado las fábulas pushkinianas como el paradigma de la atención y pasión del gran escritor por el folclore nacional ruso, abundantemente alimentadas por la imagen de la nana del poeta, Arina Rodiónovna, quien hubiera narrado a Pushkin dichas fábulas. $\mathrm{Si}$ no hay duda de que Arina Rodiónovna haya influido notablemente en el gusto por lo fantástico, el folclore y la tradición oral, es también verdad que la dimensión oleográfica del poeta, que aprende por su nana, debe ser definitivamente descartada. La creatividad y los dones artísticos de Pushkin van mucho más allá de una repetición mecanográfica de la oralidad fabulística y supera el exclusivo horizonte nacional como panorama 
de su concepción poética y política. En realidad, Pushkin intuye, a través dela composición de estas fábulas, la vasta perspectiva cultural que nace del folclore y de la tradición popular, en particular el material común a todo el patrimonio oral de la humanidad, elemento que debería hacernos reflexionar sobre el tratamiento actual destinado a la literatura llamada infantil y a la cultura popular.

En Mijáilovskoe, Pushkin pasó mucho de su tiempo escuchando a contadores de historias en las plazas y en las fiestas. Le interesó reproducir poéticamente, o sea estéticamente, el rico y variado universo de la fantasía popular, ver su conexión con la literatura y actuar con una extraordinaria modernidad: en efecto, escribiendo las Fábulas, Pushkin desjerarquiza la alta literatura y coloca un género considerado menor en la esfera de la mejor producción literaria. Como sugiere Mark Azadovski, Pushkin había genialmente intuido que «el folclore representaba la poesía de las masas populares, como expresión de la ideología de ellos, así como, al mismo tiempo, una forma especial de la creación literaria. Las Fábulas de Pushkin eran su respuesta y su intromisión en el debate sobre lo popular en literaturas.'

Las Fábulas se alimentan naturalmente del elemento popular específicamente ruso, sin dejar de lado la contribución de otras culturas próximas a Rusia, influencia que demuestra, así, no solo las amplísimas lecturas pushkinianas, sino — lo que resulta más decisivo aún - su posición crítica: el carácter internacional o supranacional del folclore y de la cultura popular. En efecto, «para Pushkin el problema de lo popular nunca fue un problema de nacionalismo, sino que él se esforzó por otorgar a la forma nacional un contenido amplio, internacional, mejor dicho, un contenido común a todo la cultura europeas. ${ }^{2}$

Este trabajo minucioso de recopilar textos orales y fuentes de culturas ajenas, para determinar la composición de fábulas donde lo poético y lo heroico viven finalmente en prodigiosa armonía, no deja de ser «aristocrático» (como algunos críticos habían llamado a Pushkin) y al mismo tiempo, se revela «populan. A través de la milagrosa perfección estética pushkiniana, las Fábulas son leídas con pasión siempre renovada por todas las generaciones rusas de niños y adultos. Las Fábulas demuestran la madurez poética de Pushkin: «la completa objetivización de la propia personalidad

\footnotetext{
'Azadovskr, Mark. «Istochniki skazok Pushkina» («Las fuentes de las fábulas de Pushkin»). En Pusblkin. Yremennik Pusbleinskoi Kommissii. Moscú-Leningrado: AN SSSR, 1936, p. 136. Traducción nuestra.

${ }^{2}$ Ibidem, pp. 161-162.
} 
creativa en la realización de un arte universal, de inmediata llegada también en los espíritus más sencillos, sin que sufriera la perfección artística». ${ }^{3}$

La «Fábula del Pescador y del Pececito» es una de las más famosas del ciclo poético de Mijáilovskoe. Llama la atención en ella «la claridad del dictado, la concisión, la férvida simplicidad. Los periodos se mueven con un dinamismo inagotable que descartalas embellecimientos y las extravagancias, recurriendo raramente a comparaciones y metáforas». ${ }^{4}$ La campesina que quiere volverse zarina y reina de todos los mares representa una figura inolvidable a través de los bosquejos pushkinianos. En este caso, Pushkin escoge material de la cultura popular rusa; sin embargo, las costumbres, las habitaciones, las realia, toda la parafernalia, utilizada como fondo de la historia del pececito dorado, no pueden ser reducidas a una sátira social, como algunos críticos habían observado. Pushkin rechaza «la falsa rusidad, el folclore de opereta». ${ }^{5}$ Más que la moraleja, que, en el crescendo poético de la fábula, es casi descontada, le interesa subrayar la riqueza poética de particulares espléndidos, la transformación del material popular en miniaturas extraordinarias, de la transmisión oral a la memoria de la página escrita, que previene el olvido y supera el tiempo. Esta es la sorprendente conclusión que se obtiene de la lectura de la fábula.

En la «Fábula del Pescador y del Pececito», Pushkin prefiere el carácter específico de la poesía, que asegura la nobleza del material y la variedad fantasiosa del universo fabulístico pushkiniano: «la sustancia de estos pequeños poemas está toda en el ritmo: un ritmo, un swing que marca los densísimos adornos de palabras intensas. Palabras que parecen siglas, pero siglas de un lúcido espesor semántico». ${ }^{6}$

Las Fábulas pushkinianas ofrecen al lector un espacio para reflexionar sobre la utilidad y el consumo de la literatura definida como «infantil», sobre su proceso de formación y sobre el problema de lo popular en la literatura entendida en términos tradicionales. Para el creador de la Hija del Capitán orientarse hacia la escritura de motivos populares o legendarios no es relacionarse con el exotismo o con el gusto populista de ideologizary enaltecer clases sociales. El folclore encuentra en la literatura y en la estética pushkinianas una justificación histórico-poética. La necesidad, además, de contextualizar permite que el lector acceda a una más noble y estimulante comprensión del folclore como una de las formas del devenir del espíritu de un pueblo. .

\footnotetext{
${ }^{3}$ Lo Gatro, Ettore. Storia della letteratura russa. Florencia: Sansón, 1979, p. 230.

${ }^{4}$ Rupelunno, Angelo Maria Ripellino. Letteratura come itinerario nel meraviglioso. Turín: Einaudi, 1968,p. 70. Traducción nuestra.

${ }^{5}$ Ibidem, p. 71.

${ }^{6}$ Ibidem, p. 70.
} 


\section{ALEIKSANDR PUSHIKIN}

\section{СКАЗКА О РЫБАКЕ И РЫБКЕ ${ }^{1}$}

Жил старик со своею старухой

У са́мого синего моря;

Они жили в ветхой землянке

Ровно тридцать Ает и три года.

Старик Аовил неводом рыбу,

Старуха пряла свою пряжу.

Раз он в море закинул невоА,

-Пришел невоА с ОАною тиной.

Он в Аругой раз закинул невоА,

-ришел невоА с травой морскою.

В третий раз - закинул он невоА,

-Пришел невод с одною рыбкой,

С непростою рыбкой, золотою.

Как взмолится золотая рыбка!

Голосом молвит человечьим:

«Отпусти ты, старче, меня в море!

Аорогой за себя Аам откуп:

Откуплюсь чем только пожелаешь».

УАивился старик, испугался:

Он рыбачим тридцать Ает и три года

И не слыхивал, чтоб рыба говорила.

Отпустил он рыбку золотую

И сказал ей масковое слово:

«Бог с тобою, золотая рыбка!

Твоего мне откупа не надо;

Ступай себе в синее море,

Гуляй там себе на просторе».

Воротился старик ко старухе,

Рассказал ей великое чудо:

\section{FÁBULA DEL PESCADOR Y DEL PECECITO}

Vivía un viejo con su esposa A la orilla de un mar azul turquí; Vivían en una decrépita casucha Hace treinta y tres años exactos.

El viejo pescaba con la red, Mientras su esposa hilaba en su telar. Una vez, al mar lanzó su red el viejo,

-Y la red volvió con solo limo.

Una vez más lanzó la red, -Y ella volvió con solo algas.

La vez tercera, la red lanzada,

La red volvió con solo un pez, Un pez insólito, —un pez de oro. ¡Cómo imploraba el pececito dorado!

Hablaba con voz de hombre: «Déjame, viejo, irme al mar!

¡Te pagaré muy bien por eso!

Te daré en recompensa lo que quieras».

Se asombró el viejo, y se asustó:

Treinta y tres años era que pescaba Y nunca había oído que un pez hablase.

Soltó, entonces, el dorado pececito

Diciéndole así unas palabras tiernas: « Ve con Dios, dorado pececito!

De ti nada necesito;

Anda al mar azul de nuevo,

Paséate por allá en plena libertad».

Regresó a su casa el viejo, Y a su esposa ese gran prodigio le contó:

\footnotetext{
' Aleksandr S. Pushkin, «Fábula del Pescador y del Pececitom. En A. S. Pushlein. Obras completas en diez volìmenes. Vol. IV. Leningrado: Nauka, 1977 («Poemas y Fábulas»),pp. 338-343. Traducción de Biagio D’Angelo.
} 
«Я сегодня поймал было рыбку, Зомотую рыбку, не простую; По-нашему говорика рыбка, Аомой в море синее просилась, Аорогою ценою откупалась: Откупалась чем только пожелаю. Не посмел я взять с нее выкуп; Так пустил ее в синее море». Старика старуха забранила: «Аурачина ты, простофиля! Не умел ты взять выкупа с рыбки! Хоть бы взял ты с нее корыто, Наше-то совсем раскололосы».

Вот пошел он к синему морю; Видит, 一море слегка разыгралось. Стал он кликать золотую рыбку, Приплыла к нему рыбка и спросика: «Чего тебе надобно, старче?» Ей с поклоном старик отвечает: «Смилуйся, государыня рыбка, Разбранила меня моя старуха, Не Аает старику мне покою: НаАобно ей новое корыто; Наше-то совсем раскололось». Отвечает золотая рыбка: «Не печалься, ступай себе с богом, Будет вам новое корыто».

\section{Воротился старик ко старухе:}

У старухи новое корыто.

Еще пуще старуха бранится: «Аурачина ты, простофиля! Выпросил, Аурачина, корыто! В корыте много Аь корысти? Воротись, Аурачина, ты к рыбке; ПокАонись ей, выпроси уж избу».

Вот пошел он к синему морю, (Помутикося синее море.)
«Hoy día he atrapado un pececito, sabes, un dorado pececito, no un pez común; como nosotros, hablaba el pececito, que lo dejase ir a su casa me pidió, me hubiera bien recompensado, me dijo, cualquier cosa le hubiese yo pedido.

No me atreví a pedirle nada a cambio, $\mathrm{Y}$ así lo dejé irse al mar azul turquís.

La vieja a reprocharle comenzó: «Qué estúpido que eres, y qué idiota! ¡No lograste sacarle nada al pececito! El barreño le hubieras podido pedir, El nuestro está totalmente requebrado.»

Y entonces se fue el viejo al mar azul turquí; $\mathrm{Y}$ vio que el mar había crecido. Comenzó a llamar fuerte al dorado pececito, Que nadó, nadó y le preguntó: «QQué quieres, viejito?»

El viejito le respondió con una reverencia: «Perdóname, señor pececito, pero es que mi vieja me ha reprochado, y no me deja en paz: un barreño nuevo quiere; el nuestro está totalmente requebrado.» Le responde el dorado pececito: «No te inquietes, vete con Dios, un nuevo barreño se le dará».

Así el viejito regresó a su casa, a su esposa:

$\mathrm{Y}$ la viejita ya tenía el nuevo barreño Pero, más fuerte aún, le reprochó al esposo: "QQué estúpido que eres, y qué idiota! No le pediste, tonto, más que un barreño! ¿Y qué ganaste con un barreño no más? Regresa, tonto, adonde el pececito; Hazle la reverencia, y pídele una iźbás.

Y entonces regresó el viejo al mar azul turquí, (el mar azul turquí se había oscurecido). 
Стал он кликать золотую рыбку, Приплыла к нему рыбка, спросила: «Чего тебе надобно, старче?»

Ей старик с поклоном отвечает: "Смилуйся, госуАарыня рыбка! Еще пуще старуха бранится, Не Аает старику мне покою: Избу просит сварливая баба». Отвечает золотая рыбка: «Не печалься, ступай себе с богом, Так и быть: изба вам уж будет». Пошел он ко своей землянке, А землянки нет уж и слеАа; ПереА ним изба со светелкой, С кирпичною, беленою трубою, С Аубовыми, тесовыми вороты. Старуха сиАит поА окошком, На чем свет стоит мужа ругает: «Аурачина ты, прямой простофиля! Выпросия, простофимя, избу! Воротись, поклонися рыбке: Не хочу быть черной крестьянкой, Хочу быть столбовою Аворянкойм.

Пошел старик к синему морю; (Не спокойно синее море.) Стал он кликать золотую рыбку. Приплыла к нему рыбка, спросила: «Чего тебе надобно, старче?»

Ей с поклоном старик отвечает: «Смикуйся, государыня рыбка! Пуще прежнего старуха взАурилась, Не Аает старику мне покою: Уж не хочет быть она крестьянкой, Хочет быть столбовою Аворянкой). Отвечает золотая рыбка: «Не печалься, ступай себе с богом».

Воротился старик ко старухе. Что ж он виАит? Высокий терем.
Comenzó a llamar al dorado pececito, Nadó, nadó el pececito y le preguntó: «QQué quieres, viejito?»

El viejito le respondió con una reverencia: «Perdóname, señor pececito, pero es que mi vieja de nuevo me ha gritado, y no me deja en paz: una iz̧bá aquella bruja gruñona ahora quiere». Le respondió el dorado pececito: «No te inquietes, vete con Dios, una nueva izbá se le dará». Se fue el viejito a su casucha, Mas de ella ni una huella: En frente de él, había una iz̧bá con claraboya, Una estufa nuevecita, de ladrillos, El portón de roble, majestuoso. La viejita, sentada a la ventana, al esposo maldecía: «Qué estúpido que eres, y qué idiota! No le pediste, tonto, más que una $i \not ̨ b a$ !

Regresa, arrodillate ante al pececito: Ya no quiero ser una campesina pobretona, Quiero ser ahora una dama de linaje noble».

El viejito se fue al mar azul turquí; (no era calmo el mar azul turquí.) Comenzó a llamar al dorado pececito. Nadó, nadó el pececito y le preguntó: "¿Qué quieres, ahora, viejito?» Le respondió con una reverencia: «Perdóneme, señor pececito! Mi vieja mucho más que antes se ha enojado, No me deja en paz esta mujer: Ya no quiere vivir de campesina, Sino ser dama de noble linaje». Le responde el dorado pececito: «No te inquietes, vete con Dios».

Regresa el viejito a su casa, a su esposa. $\mathrm{Y}$ ¿qué ahora ve? Un castillo enorme, enorme. 
На крыльце стоит его старуха

В Аорогой собольей Аушегрейке,

Парчовая на маковке кичка,

Жемчуги огрузили шею,

На руках золотые перстни,

На ногах красные сапожки.

ПереА нею усерАные слуги;

Она бьет их, за чупрун таскает.

Говорит старик своей старухе:

«ЗАравствуй, барыня сударыня Аворянка!

Чай, теперь твоя Аушенька Аовольнал,

На него прикрикнула старуха,

На конюшне служить его послала.

Вот неАеля, Аругая прохоАит,

Еще пуще старуха взаурилась;

Опять к рыбке старика посынает.

«Воротись, поклонися рыбке:

Не хочу быть столбовою Аворянкой,

А хочу быть вольною царицей».

Испугался старик, взмолился:

«Что ты, баба, белены объелась?

Ни ступить, ни молвить не умеешь!

Насмешишь ты целое царство».

ОсерАилася пуще старуха,

По щеке уАарима мужа.

«Как ты смеешь, мужик, спорить со мною,

Со мною, Аворянкой столбовою?

- Ступай к морю, говорят тебе честью,

Не пойАешь, повеАут поневоле».

Старичок отправияся к морю,

(Почернело синее море.)

Стал он кликать золотую рыбку.

Приплыла к нему рыбка, спросила:

«Чего тебе налобно, старче?»

Ей с поклоном старик отвечает:

«Смилуйся, государыня рыбка!

Опять моя старуха бунтует:

Уж не хочет быть она Аворянкой,
En el patio está su vieja

Con un manto de visón,

$\mathrm{Y}$ un sombrero de brocado, Unas perlas el cuello le adornan, En los dedos, anillos preciosos, En los pies, finas botas, rojo carmesí.

En su presencia, siervos celosos; Ella les pega, les arrastra por el caftán.

Dice el viejo a su esposa: «Buenos días, mi señora, mi doña, mi dueña!

Ahora, a lo que veo, bien satisfecha estás».

Mas la vieja la voz le levantó,

Y a trabajar en la caballeriza lo mandó.

Y así una semana, otra semana pasó,

Siempre más la vieja se enojaba;

Y manda el viejito nuevamente donde el pececito.

«Regresa ahí, arrodillate ante el pececito:

ya no quiero ser una dama de noble linaje, quiero ser una altiva zarinas,

El viejito se asustó y le imploraba: «Qué te pasa, vieja, te has comido clavos?

Pero si no sabes ni hablar ni caminar!

El hazmerreír serás para tu reino».

Siempre más la vieja se enojaba,

$\mathrm{Y}$ así le dio a su esposo un bofetón.

«iCómo osas, hombre, conmigo discutir, conmigo, dama de noble linaje!»

-Anda al mar, haz lo que te pido, Si no quieres, irás igual».

El viejito se fue al mar,

(el mar azul turquí ya estaba todo negro.)

Llamó fuerte al dorado pececito.

Nadó, nadó el pececito y le preguntó: «¿Qué quieres, viejo, ahora?»

Le responde con una reverencia: «Perdóneme, señor pececito!

Es que mi esposa protestá nuevamente:

Ahora ya no quiere ser dama, 
Хочет быть вольною царицей».

Отвечает золотая рыбка:

«Не печалься, ступай себе с богом!

Аобро! будет старуха царицей!»

Старичок к старухе воротился.

Что ж? преА ним царские палаты.

В палатах видит свою старуху,

За столом сидит она царицей,

Служат ей бояре Аа Аворяне,

Наливают ей заморские вины;

ЗаеАает она пряником печатным;

Вкруг ее стоит грозная стража,

На плечах топорики держат.

Как увидел старик, 一испугался!

В ноги он старухе поклонился,

Молвил: «ЗАравствуй, грозная царица!

Ну теперь твоя Аушенька Аовольна».

На него старуха не взглянула,

$\Lambda$ ишь с очей прогнать его велела.

Подбежали бояре и Аворяне,

Старика взашеи затолкали.

А в Аверях-то стража подбежала,

Топорами чуть не изрубика.

А народ-то наА ним насмеялся:

«Поделом тебе, старый невежа!

Впредь тебе, невежа, наука:

Не садися не в свои сани!»

Вот недемя, Аругая проходит,

Еще пуще старуха вздурикась.

Царедворцев за мужем посылает,

Отыскали старика, привели к ней.

Говорит старику старуха:

«Воротись, покмонися рыбке.

Не хочу быть вольною царицей,

Хочу быть владычицей морскою,

Чтобы жить мне в Окияне-море,

Чтобы служила мне рыбка золотая

И была 6 у меня на посылках».
Quiere ser una zarina altiva». Le responde el dorado pececito: «iNo te inquietes, vete con Dios! Está bien. ¡Tu vieja zarina será!»

$\mathrm{El}$ viejito regresa adonde su esposa. $\mathrm{Y}$ ¿qué pasó? Ve salas de palacio.

En una de ellas, estaba su vieja, a una mesa sentada, como zarina.

La sirven boyaros y cortesanos,

Le ofrecen vinos de ultramar; Se delicia con un biscocho bien cocido;

A su entorno guardias amenazadores, Armadas de bayonetas.

Apenas las vio el viejito, jse asustó! Se arrodilló a su esposa,

Y le dijo: «iBuenos días, severa zarina!

Ahora sí que estás complacida».

Mas la vieja ni le echó un vistazo,

Que con los ojos ordenó que afuera lo botasen.

Acudieron así boyaros y cortesanos,

Y sacaron al viejito de mal modo.

Además, en la entrada, acudió también la guardia,

Que casi lo matan a machetazos.

Y todo el pueblo se reía:

«Bien merecido, viejo rústico!

Así aprendes, ignorante, la lección:

¡Nunca meterse en donde no se debel».

Y así una semana, otra semana pasó,

Siempre más la vieja se enojaba.

$\mathrm{Y}$ a llamar al esposo manda a sus guardias.

Lo encontraron y antes de ella lo llevaron.

Dijo la vieja al viejecito:

«Regresa, arrodillate ante el pececito.

Ya no quiero ser una zarina altiva,

Mas quiero ser de todos los mares la dueña,

Para vivir en el Océano,

Y para que a mí sola me sirva el dorado pececito,

Y sea mi mandadero personal». 
Старик не осмелился перечить, Не Аерзнул поперек слова молвить. Вот иАет он к синему морю, Вилит, на море черная буря:

Так и взАулись серАитые волны, Так и ходят, так воем и воют. Стал он кликать золотую рыбку, Приплыла к нему рыбка, спросила: «Чего тебе надобно, старче?» Ей старик с поклоном отвечает: «Смилуйся, государыня рыбка!

Что мне Аелать с проклятою бабой? Уж не хочет быть она царицей, Хочет быть вАадычицей морскою; Чтобы жить ей в Окияне-море, Чтобы ты сама ей служила И была бы у ней на посылках». Ничего не сказала рыбка, Аишь хвостом по воде плеснула И ушла в глубокое море. Аолго у моря жАал он ответа, Не АожАался, к старухе воротился -ГАяАь: опять переА ним землянка; На пороге сидит его старуха, А преА нею разбитое корыто.
El viejito no se atrevió a contradecirla, Y el coraje no tuvo de proferir palabra. $\mathrm{Y}$ así se fue al mar azul turquí, $Y$ vio en el mar una negra tempestad: Las olas se levantaban furiosas, Altas se acercaban y aullaban. Llamó entonces al dorado pececito, Que nadó, nadó hacia él y le preguntó: "QQué quieres ahora, viejito?» Le responde el viejo con una reverencia: «Perdóname, señor pececito!

¿Qué tengo que hacer con esta mujer maldita?

Ni siquiera zarina ya quiere ser, Quiere ser ahora la dueña de los mares, Para vivir, ella, en el Océano, Y para que tú le sirvas Y que le seas su personal mandadero». Nada le contestó el dorado pececito, Solo zambulló, retirándose, en el agua, $\mathrm{Y}$ desapareció en el profundo mar. Largo tiempo esperó respuesta el viejecito, mas se cansó, y regresó a su vieja -Y ¿qué ve? Su casucha nuevamente, Esperando su vieja en el umbral, $\mathrm{Y}$ un barreño requebrado cerca de ella. 